\title{
Taxonomy and molecular phylogeny of the Asian Paraleucophenga Hendel (Diptera, Drosophilidae)
}

\author{
FENG $\mathrm{ZHAO}^{1} \uparrow$, JIAN-JUN GAO ${ }^{2} \dagger$ and HONG-WEI $\mathrm{CHEN}^{1 *}$ \\ ${ }^{1}$ Department of Entomology, South China Agricultural University, Tianhe, Guangzhou, Guangdong \\ 510642, China \\ ${ }^{2}$ Laboratory for Conservation and Utilization of Bioresource, Yunnan University, Kunming, Yunnan \\ 650091, China
}

Received 8 October 2007; accepted for publication 14 January 2008

\begin{abstract}
This paper reports on nine Asian species of the genus Paraleucophenga, of which four are new to science: Paraleucophenga brevipenis sp. nov., Paraleucophenga hirtipenis sp. nov., Paraleucophenga longiseta sp. nov., and Paraleucophenga tanydactylia sp. nov. We also report on a new synonym, Paraleucophenga shanyinensis Chen \& Toda, 1994 syn. nov. A key to all of the species examined, based on morphological data, is provided, together with a 'molecular' key to seven Paraleudophenga species based on DNA sequence data of the mitochondrial NADH dehydrogenase subunit 2 (ND2) gene. The phylogenetic relationships among seven Paraleucophenga species are reconstructed based on DNA sequences of the mitochondrial ND2 gene, using two Leucophenga species as outgroups. (c) 2009 The Linnean Society of London, Zoological Journal of the Linnean Society, 2009, 155, 615-629.
\end{abstract}

ADDITIONAL KEYWORDS: East Asia - mtDNA - new species - new synonym - Steganinae.

\section{INTRODUCTION}

The genus Paraleucophenga Hendel, 1914 of the subfamily Steganinae was known from one Afrotropical and seven Oriental species (Walker, 1857; Okada, 1956, 1988; Bächli, 1971; Singh \& Negi, 1992; Chen \& Toda, 1994; Sidorenko, 1998). Adults of Paraleucophenga are slender, but are relatively large in body size (i.e., body length) $(\sim 4-5 \mathrm{~mm})$. The adults surround humans at the forest edge, where they can also be collected from tree trunks, but are very difficult to detect in dim forest. In comparison with adults of Paraleucophenga, adults of the genera Amiota Loew, 1982 and Phortica Schiner, 1862 seldom appear around humans at the forest edge, but pursue humans in the forest.

Okada (1989) assigned the genus Paraleucophenga in the tribe Leucophengini, along with the genus Leucophenga Mik, 1886, based on a phenetic analysis with 14 adult morphological characters. Whereas Grimaldi (1990), based on a cladistic analysis of 217

*Corresponding author. E-mail: hongweic@scau.edu.cn $\dagger$ These authors contributed equally to the present study. adult characters, assigned Paraleucophenga in the tribe Gitonini, along with some other genera (e.g. Amiota, Cacoxenus Loew, 1858, and Gitona Meigen, 1830). Morphological similarity between Paraleucophenga and Leucophenga, such as the silvery pollinosity on male scutum and abdominal tergites (Figs 1-8), supports Okada's classification; whereas the behavioral similarity between Paraleucophenga and Amiota favour Grimaldi's proposal.

Lin \& Wheeler (1972) described the abdominal colour pattern of Paraleucophenga invicta (Walker, 1857) in a female specimen. However, this character is usually much less variable in females than in males among species. In the present study we taxonomically surveyed ten species of Paraleucophenga from East and South East Asia, four of which were found in southern China and are described as new species; and found that the fifth sternites of males vary (Figs 9-15). Phylogenetic relationships among eight (as one species is present as a junior synonym of another, there are actually seven) of these species are investigated based on DNA sequences of the mitochondrial $N A D H$ dehydrogenase subunit 2 (ND2) gene, using two Leucophenga species as outgroups. 


\section{MATERIAL AND METHODS \\ TAXON SAMPLING}

The examined specimens are deposited in the following institutions: Kunming Institute of Zoology, Chinese Academy of Sciences (KIZ); Department of Zoology, National Science Museum, Tokyo, Japan (NSMT); Department of Entomology, South China Agricultural University (SCAU); and Systematic Entomology, the Hokkaido University Museum, Hokkaido University, Sapporo, Japan (SEHU).

For taxonomical terminology and indices, see Chen \& Toda (2001). New records are indicated by an asterisk (*).

\section{SAMPLES FOR MOLECULAR PHYLOGENETIC STUDY}

Eight Paraleucophenga species, each represented by between one and five populations, were sampled for phylogenetic analyses. Two Leucophenga species, each represented by a single population, were used as outgroups. The collection data for all of these samples are shown in Table 1.

\section{DNA EXTRACTION, PCR, AND SEQUENCING}

Samples were preserved in $70 \%$ ethanol immediately after collection. Total DNA was extracted from part of a single fly using the standard phenol/chloroform method (Sambrook, Fritsch \& Maniatis, 1989), with a slight modification. The primers used to amplify the
ND2 gene were 5'-AAGCTACTGGGTTCATACC-3' (forward; Park, 1999) and 5'-ATATTTACAGCTTTGA AGG-3' (reverse; designed specifically for the present study). The PCR reaction mixture $(25 \mu \mathrm{L})$ contains $0.4 \mu \mathrm{mol}$ of each primer, $0.2 \mathrm{mmol}$ of each deoxyribonucleoside triphosphate (dNTP), $2.5 \mathrm{mmol} \mathrm{MgCl}_{2}$, and $0.5 \mathrm{U}$ of $\mathrm{Taq}$ polymerase. Each of the 35 thermocycles included $1 \mathrm{~min}$ denaturing at $94{ }^{\circ} \mathrm{C}, 1 \mathrm{~min}$ annealing at $54{ }^{\circ} \mathrm{C}$, and $1 \mathrm{~min}$ elongation at $72{ }^{\circ} \mathrm{C}$. The purified PCR product was then subjected to a sequencing reaction. For a few samples, the purified products were cloned into pMD20-T vector, and were then transformed into Escherichia coli TG-1 as a host. Then some positive clones were selected, and one of them was used as the template for sequencing reactions. The sequences were determined using an ABI 3730 automatic sequencer. Accession numbers for all of the newly determined sequences are listed in Table 1 .

\section{TEST OF NUCLEOTIDE SUBSTITUTION SATURATION}

Substitution saturation resulting from multiple changes at the same site can overwhelm the phylogenetic signal, and can thus effect the phylogenetic reconstruction. It was shown that phylogenetic information is essentially lost when the observed index of substitution saturation (Iss) in sequences exceeds the critical index of substitution saturation (Iss. c)

Table 1. Collection data of samples, and accession numbers of the sequences newly determined in this study

\begin{tabular}{|c|c|c|c|}
\hline Samples & Collection site & $\begin{array}{l}\text { Latitude and } \\
\text { longitude }\end{array}$ & $\begin{array}{l}\text { Accession } \\
\text { No. }\end{array}$ \\
\hline Leucophenga angusta & Tokyo, Japan & $35^{\circ} 36^{\prime} \mathrm{N}, 139^{\circ} 23^{\prime} \mathrm{E}$ & EU180490 \\
\hline Leucophenga quadripunctata & Tokyo, Japan & $35^{\circ} 36^{\prime} \mathrm{N}, 139^{\circ} 23^{\prime} \mathrm{E}$ & EU180491 \\
\hline Paraleucophenga argentosa-YJ & Yamanashi, Japan & $35^{\circ} 39^{\prime} \mathrm{N}, 139^{\circ} 07^{\prime} \mathrm{E}$ & EU180492 \\
\hline Paraleucophenga argentosa-KJ & Kumamoto, Japan & $32^{\circ} 37^{\prime} \mathrm{N}, 130^{\circ} 51^{\prime} \mathrm{E}$ & EU180493 \\
\hline Paraleucophenga shanyinensis & Huajiang, Guangxi, China & $25^{\circ} 51^{\prime} \mathrm{N}, 110^{\circ} 27^{\prime} \mathrm{E}$ & EU180494 \\
\hline Paraleucophenga emeiensis-JX & Guanshan, Jiangxi, China & $28^{\circ} 30^{\prime} \mathrm{N}, 114^{\circ} 31^{\prime} \mathrm{E}$ & EU180495 \\
\hline Paraleucophenga emeiensis-YN & Xishuangbanna, Yunnan, China & $21^{\circ} 41^{\prime} \mathrm{N}, 101^{\circ} 25^{\prime} \mathrm{E}$ & EU180496 \\
\hline Paraleucophenga emeiensis-SC & Fengtongzhai, Sichuan, China & $30^{\circ} 34^{\prime} \mathrm{N}, 102^{\circ} 53^{\prime} \mathrm{E}$ & EU180497 \\
\hline Paraleucophenga emeiensis-FJ & Wuyishan, Fujian, China & $27^{\circ} 43^{\prime} \mathrm{N}, 117^{\circ} 57^{\prime} \mathrm{E}$ & EU180498 \\
\hline Paraleucophenga javana-YN & Xishuangbanna, Yunnan, China & $21^{\circ} 41^{\prime} \mathrm{N}, 101^{\circ} 25^{\prime} \mathrm{E}$ & EU180499 \\
\hline Paraleucophenga javana-GX & Nonggang, Guangxi, China & $22^{\circ} 22^{\prime} \mathrm{N}, 106^{\circ} 51^{\prime} \mathrm{E}$ & EU180500 \\
\hline Paraleucophenga javana-GD & Zhaoqing, Guangdong, China & $23^{\circ} 10^{\prime} \mathrm{N}, 112^{\circ} 34^{\prime} \mathrm{E}$ & EU180501 \\
\hline Paraleucophenga tanydactylia sp. nov. & Xishuangbanna, Yunnan, China & $22^{\circ} 20^{\prime} \mathrm{N}, 100^{\circ} 51^{\prime} \mathrm{E}$ & EU180507 \\
\hline Paraleucophenga brevipenis sp. nov.-GD1. & Nanling, Guangdong, China & $25^{\circ} 00^{\prime} \mathrm{N}, 113^{\circ} 24^{\prime} \mathrm{E}$ & EU180502 \\
\hline Paraleucophenga brevipenis sp. nov.-GD2 & Nanling, Guangdong, China & $25^{\circ} 00^{\prime} \mathrm{N}, 113^{\circ} 24^{\prime} \mathrm{E}$ & EU180503 \\
\hline Paraleucophenga hirtipenis sp. nov. & Shibalianshan, Yunnan, China & $25^{\circ} 12^{\prime} \mathrm{N}, 104^{\circ} 35^{\prime} \mathrm{E}$ & EU180506 \\
\hline Paraleucophenga longiseta sp. nov.-JX & Guanshan, Jiangxi, China & $28^{\circ} 30^{\prime} \mathrm{N}, 114^{\circ} 31^{\prime} \mathrm{E}$ & EU180504 \\
\hline Paraleucophenga longiseta sp. nov.-GX & Maoershan, Guangxi, China & $25^{\circ} 51^{\prime} \mathrm{N}, 110^{\circ} 27^{\prime} \mathrm{E}$ & EU180505 \\
\hline
\end{tabular}




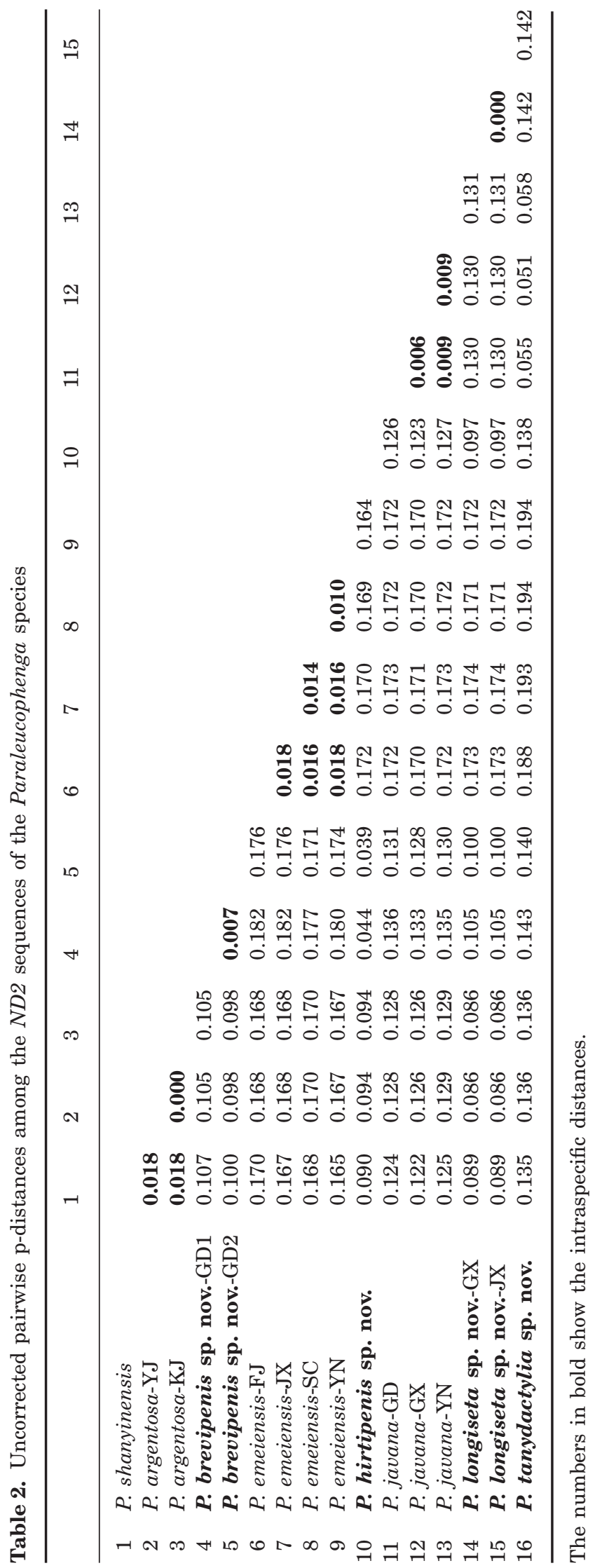


(Xia et al., 2003). We used the program DAMBE4.5.32 to test whether Iss was lower than Iss. c.

\section{DiAgNosing PARALEUCOPHENGA SPECIES USING DNA SEQUENCES}

All the ND2 sequences, including those of the outgroup taxa, were aligned using the ClustalW (Thompson, Higgins \& Gibson, 1994) method, and were then modified manually. The resulting alignment was used for diagnostic character (nucleotide position) selection, the DNA substitution model test, as well for phylogenetic reconstruction. Groups of nucleotide positions were selected as characters to diagnose different taxa (pairs of species or species clusters) in the genus Paraleucophenga. For this, less degenerated positions showing amino acid replacement between (but not within) the two taxa compared were preferentially considered. A 'molecular' key using the selected positions as diagnostic characters was elaborated to distinguish between the Paraleucophenga species for which ND2 sequences were available.

\section{PHYLOGENETIC ANALYSIS}

A DNA substitution model was selected using Modeltest 3.7 (Posada \& Crandall, 1998), and phylogenetic analyses were performed with the maximum parsimony (MP) and maximum likelihood (ML) methods using PAUP*4.0b10 (Swofford, 2003), and with the Bayesian inference (BI) method using MrBayes 3.1 (Ronquist \& Huelsenbeck, 2003). Sites with gaps were treated as missing data in the MP analysis, but were completely deleted in the ML and BI analyses. Calculation of basic statistical quantities of DNA sequences were implemented in MEGA 3.1 (Kumar, Tamura \& Nei, 2004). The heuristic search of MP trees was performed with initial trees obtained by 100 replicates of random addition, and branch swapping using the tree bisection and reconnection (TBR) algorithm. The K81uf + G (two transversion parameters, model 1 , unequal frequencies, and a gamma-distributed substitution rate across sites) model was selected for the ML analysis, with parameters assigned as follows: base frequencies of $\mathrm{A}, \mathrm{C}, \mathrm{G}$, and $\mathrm{T}$ are $0.3695,0.0974,0.0584$, and 0.4746 , respectively; substitution rates for the classes A-C, A-G, A-T, C-G, C-T, and G-T were $1.0000,12.7822,1.9286,1.9286,12.7822$, and 1.0000, respectively; the proportion of invariable sites $=0$; gamma distribution shape parameter $=0.2820$. For the Bayesian analysis with MrBayes 3.1 (Ronquist \& Huelsenbeck, 2003), a site-specific rate model was used, allowing the first codon position to have six substitution types, whereas the second and third codon positions were only allowed to have two substitution types. For all of the codon positions, a gamma-distributed rate was assumed. For the MP and ML analyses, the bootstrap percentages (BPs; 1000 replicates) were calculated to evaluate the node confidences.

\section{TAXONOMIC ACCOUNT}

Paraleucophenga HENDEL, 1914

Paraleucophenga Hendel, 1914: 114.

Type species: Helomyza invicta Walker, 1857: 130.

Diagnosis: Modified from Bächli (1971) and Okada (1988). Frons narrow, less than one third of head width; arista with long dorsal and fine ventral branches; scutellum usually with small setae along margin; katepisternal setae 3 ; abdominal tergites with silvery white pollinosity; cercus elongated below and slightly constricted submedially (Figs 16, 18, 20, 22); paramere with tooth comb (Figs 17, 19, 21, 23); aedeagal apodeme sub-basally narrow, arched, distally broadened (Figs 17, 19, 21, 23).

Description: Body slender, usually longer than $4.0 \mathrm{~mm}$.

Head: Eye dark red. Ocellar triangle: black, with one pair of small setae above ocellar setae. Frons dark brown, with one row of interfrontal setulae along fronto-orbital plate. Pedicel brown. First flagellomere grey yellow. Face grey yellow, facial carina not prominent. Clypeus grey yellow. Gena: narrow and linear, yellowish. Postgena yellow. Vibrissa prominent; other orals small. Palpus slender, basally grey yellow, distally black, with a few small setae along ventral margin. Occiput glossy, brownish black.

Thorax: yellow, with brown patches and silvery pollinosity. Postpronotal lobe pale yellow, with one long and a few short setae. Acrostichal setulae in approximately ten irregular rows. Prescutellar setae one pair. Anepisternum glabrous. Scutellum usually concolorous with thorax, with one obscure patch. Basal scutellar setae divergent; apicals cruciate.

Wing: brownish. Basal medial-cubital crossvein absent; $\mathrm{C}_{1}$ setae 2 , indistinctly differentiated. $\mathrm{R}_{2+3}$ : 
slightly curved to costa at tip. $\mathrm{R}_{4+5}$ and $\mathrm{M}_{1}$ nearly parallel. Halters grey white.

Legs: yellow. Fore femur with two or three irregular rows of long setae on posterior surface. Preapical and apical dorsal setae present on all tibiae. Fore- and mid first tarsomeres each as long as other tarsomeres combined; hind first tarsomere as long as the three succeeding tarsomeres together.

Abdomen: Males tergites 1-5 with dense silvery white pollinosity, and with brown to dark brown coloration. Females yellow, with distinct pattern (Lin \& Wheeler, 1972; Fig. 5B). Sternites usually grey yellow.

Male terminalia: Epandrium slightly constricted mid-dorsally, broadened below, nearly entirely pubescent, except for ventral margin, with dense setae (Figs 16, 18, 20, 22). Cercus separated from epandrium, entirely pubescent, and setigerous (Figs 16, $18,20,22$ ). Surstylus quadrate, with a few setae on outer surface, and small prensisetae on apical margin (Figs 16, 18, 20, 22). Membrane between epandrium and cercus pubescent (Figs 16, 18, 20, 22). Hypandrium narrow, arched, sub-basally with one pair of somewhat triangular plates (Figs 17, 19, 21, 23). Gonopods fused to each other, forming posteromedian plate, anteriorly forming contiguous to aedeagus (basiphallus) (Figs 17, 19, 21, 23). Parameres sub-basally and apically with a few sensilla (Figs 17, 19, 21, 23). Aedeagus: short and thick, membranous tube with pubescence distally (Figs 17, $19,21,23)$.

Included species: Paraleucophenga semiplumata (Duda, 1939); Paraleucophenga argentosa (Okada, 1956); Paraleucophenga emeiensis Sidorenko, 1998; Paraleucophenga invicta (Walker, 1857); Paraleucophenga javana Okada, 1988; Paraleucophenga neojavanaii Singh \& Negi, 1992; Paraleucophenga shimai Okada, 1988; Paraleucophenga brevipenis sp. nov.; Paraleucophenga hirtipenis sp. nov.; Paraleucophenga longiseta sp. nov., and Paraleucophenga tanydactylia sp. nov.

Key to ALL PARALEUCOPHENGA SPECIES EXAMINED, BASED ON MALE MORPHOLOGICAL DATA

1. Frons narrow, less than one third of head width; arista with long dorsal and fine ventral branches; scutellum usually with small setae along margin; katepisternal setae 3; abdominal tergites with silvery white pollinosity; cercus elongated below and slightly constricted submedially; paramere with tooth comb; aedeagal apodeme sub-basally narrow, arched, distally broadened; (genus Paraleucophenga) ......................................2

2. Scutellum without setae along margin; midleg femur medially with one row of about five strong setae on anterior surface; thorax and abdominal tergites with silvery white pollinosity.................................... shimai Scutellum with small setae along margin; midleg femur lacking strong setae on anterior surface; thorax and

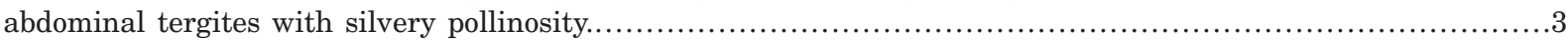

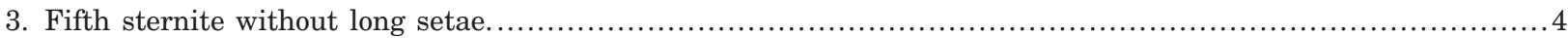

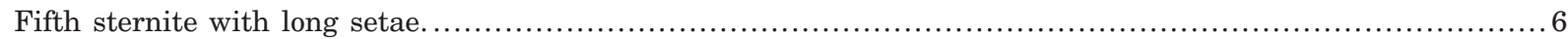

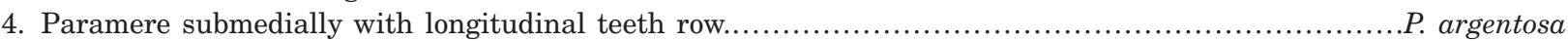

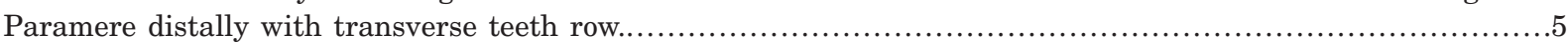

5. Brown posterior band of third tergite as broad as half of the tergite width; fifth tergite nearly entirely dark brown, with one yellow patch laterally.............................................................. emeiensis Brown posterior band of third tergite as broad as a fifth of the tergite width; posterior band of fifth tergite as broad as two thirds of the tergite width, laterally dark ...................................................... invicta

6. First tergite silvery white; fifth sternite with long finger-like processes, lacking spinules along posterior margin.

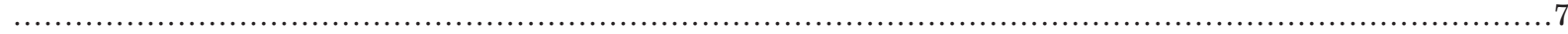
First tergite dark brown; fifth sternite with a few spinules along posterior margin, lacking long finger-like processes.

7. Brown posterior band of second tergite submedially as broad as half of the tergite width; fifth sternite with six long,

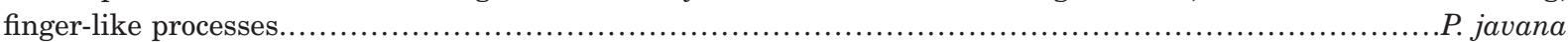
Brown posterior band of second tergite as broad as a third of the tergite width; fifth sternite with 12 long, finger-like

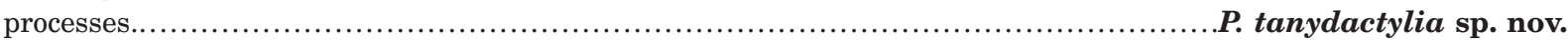

8. Fifth sternite with 22-23 long and strong setae; gonopods subapically with one sclerotized right process; aedeagal apodeme distally with one sclerotized right process..................................... brevipenis sp. nov. Fifth sternite with 16-18 long and strong setae; gonopods subapically with one sclerotized left process.............9

9. Aedeagal apodeme distally with one sclerotized left process.............................. hirtipenis sp. nov. Aedeagal apodeme distally with one sclerotized right process.................................. longiseta sp. nov. 


\section{KeY TO SEVEN PARALEUCOPHENGA SPECIES BASED ON THE ND2 GENE SEQUENCES}

In the following key to seven Paraleocophenga species, each of the numbers indicates the position of a diagnostic character in the affiliated sequences, followed by its status (i.e. nucleotide type, given after a colon) and (after a slash) corresponding amino acid type (all shown in standard three-letter abbreviations; in the case of more than two types of amino acid being present, they are bracketed together, and are separated from each other using an additional slash).

1. 251: T/Met; 596: T/Ile; 653: A/Tyr; 671: G/Ser; 689: T/Phe; 827: C/Thr; 839: T/Val...................... emeiensis 251: C/(Ser/Thr); 596: C/Thr; 653: T/Phe; 671: A/Asn; 689: A/His; 827: T/Met; 839: G/Ser........................2

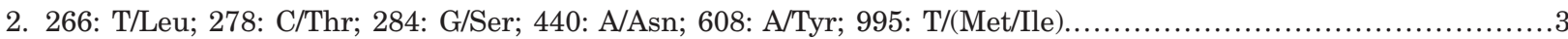
266: C/Ser; 278: T/Ile; 284: T/Met; 440: C/Thr; 608: T/Phe; 995:G/Ser............................................

3. 46: A/Thr; 223: G/Val; 452: T/Lle; 637: T/Leu; 955: A/Met; 1019: T/Met................................ javana 46: G/Ala; 223: A/Ile; 452: C/Thr; 637: A/Met; 955: G/Val; 1019: C/Thr................... tanydactylia sp. nov.

4. 106: G/Val; 275: G/Ser; 682: A/Thr; 926: A/Asn; 967: T/Phe; 1015: A/Ile.....................................

106: A/Ile; 275: A/Asn; 682: T/Ser; 926: T/Phe, 967: A/Met; 1015: T/Phe.....................................6

5. 452: C/Thr; 799: T/Ser; 809: A/Asn; 883: G/Ala; 905: T/Phe............................ P. brevipenies sp. nov. 452: T/Ile; 799: A/Thr; 809: G/Ser; 883: T/Ser; $905 \mathrm{~A} /$ Tyr.................................... hirtipenis sp. nov.

6. 70: G/Ala; 205: A/Thr; 314: G/Ser; 604: G/Val; 932: C/Ser; 935: A/Lys; 941: C/Thr............P. longiseta sp. nov. 70: T/Ser; 205: T/Ser; 314: C/Thr; 604: A/Met; 932: T/Leu; 935: G/Ser; 941: A/Asn..................... argentosa

\section{PARALEUCOPHENGA ARGENTOSA (OKADA, 1956)} (FIGS 1, 9)

Leucophenga (Trichiaspiphenga) argentosa Okada, 1956: 24 (synonymized as $P$. invicta by Okada, 1988: 620).

Paraleucophenga shanyinensis Chen \& Toda, 1994: 71 syn. nov.

Specimens examined: Japan: paratypes, two males, one female, Setagawa, Tokyo, 2.iv.1954, T. Okada (NSMT); two males, Ueinohara, Yamanashi, 12.viii.2002, ex. around human eyes, H.W. Chen; two males, one female, Tomochi, Kumamoto, 17.viii.2002, ex. around human eyes, H.W. Chen. China: one male, Huajiang, Guilin, Guangxi, 9.ix.2001, H. Watabe.

Distribution: Japan (Honshu and Kyushu) and China (Anhui, Zhejiang, and Guangxi).

Remarks: Okada (1988) checked a specimen of $P$. invicta (Walker, 1857) from the type locality (Taiwan), and thought that $P$. argentosa was a synonym of $P$. invicta. After examining these specimens, we confirmed that the two forms are actually different species. In fact, Okada (1988) mistook the anteroventral processes of the gonopod for the paramere, and thus concluded that $P$. argentosa was a synonym of $P$. invicta. On the other hand, no morphological diagnostic character has been found to discern between $P$. argentosa and $P$. shanyinensis, thereby supporting $P$. shanyinensis as a new synonym.

\section{PARALEUCOPHENGA EMEIENSIS SIDORENKo, 1998} (FIGS 2, 10)

Specimens examined: China: holotype male, Emeishan, Sichuan, 550 m a.s.l., M.J. Toda (SEHU). China: three males, two females, Wuyishan, Fujian, $700 \mathrm{~m}$ a.s.l., 17.viii.2001, on tree trunks, H.W. Chen; two males, Guanshan, Yifeng, Jiangxi, $500 \mathrm{~m}$ a.s.l., 8.vi.2004, ex. around human eyes, J.J. Gao; one male, Nonggang, Longzhou, Guangxi, $550 \mathrm{~m}$ a.s.l., 5.vi.1993, ex. around human eyes, Y.S. Cui; two males, Emeishan, Leshan, Sichuan, 1700 m a.s.l., 4.vii.2007, ex. around human eyes, H.Z. Cao and J.J. Jiang; one male, Fengtongzhai, Baoxing, Sichuan, 1600 m a.s.l., 18.ix.2005, H.W. Chen; one male, Leigongshan, Kaili, Guizhou $\left(\sim 26^{\circ} 24^{\prime} \mathrm{N}, 108^{\circ} 19^{\prime} \mathrm{E}\right), 800 \mathrm{~m}$ a.s.l., 16.vii.2000, ex. around human eyes, J.J. Gao; five males, Menglun, Xishuangbanna, Yunnan, 14.ix.2002, 24-26.xii.2004, 17-20.iv.2007, 600-900 m a.s.l., ex. around human eyes, H.W. Chen and J.J. Gao.

Distribution: China (Fujian, Jiangxi, Guangxi, Sichuan, Guizhou, and Yunnan).

\section{PARALEUCOPHENGA INVICTA (WALKER, 1857)} (FIG. 3)

Helomyza invicta Walker, 1857: 130 (Borneo?).

Leucophenga (Trichiaspiphenga) invicta: Duda, 1924: 185 (Taiwan).

Paraleucophenga invicta: Lin \& Wheeler, 1972: 248 (Taiwan; Nepal); Okada, 1988: 620 (Taiwan; Malaysia, Sarawak).

Paraleucophenga triseta Hendel, 1914: 114 (Taiwan).

Specimens examined: China: one male, one female, Kuantsuling, Tainan, Taiwan, 6.vi.1965, T. Saigusa 

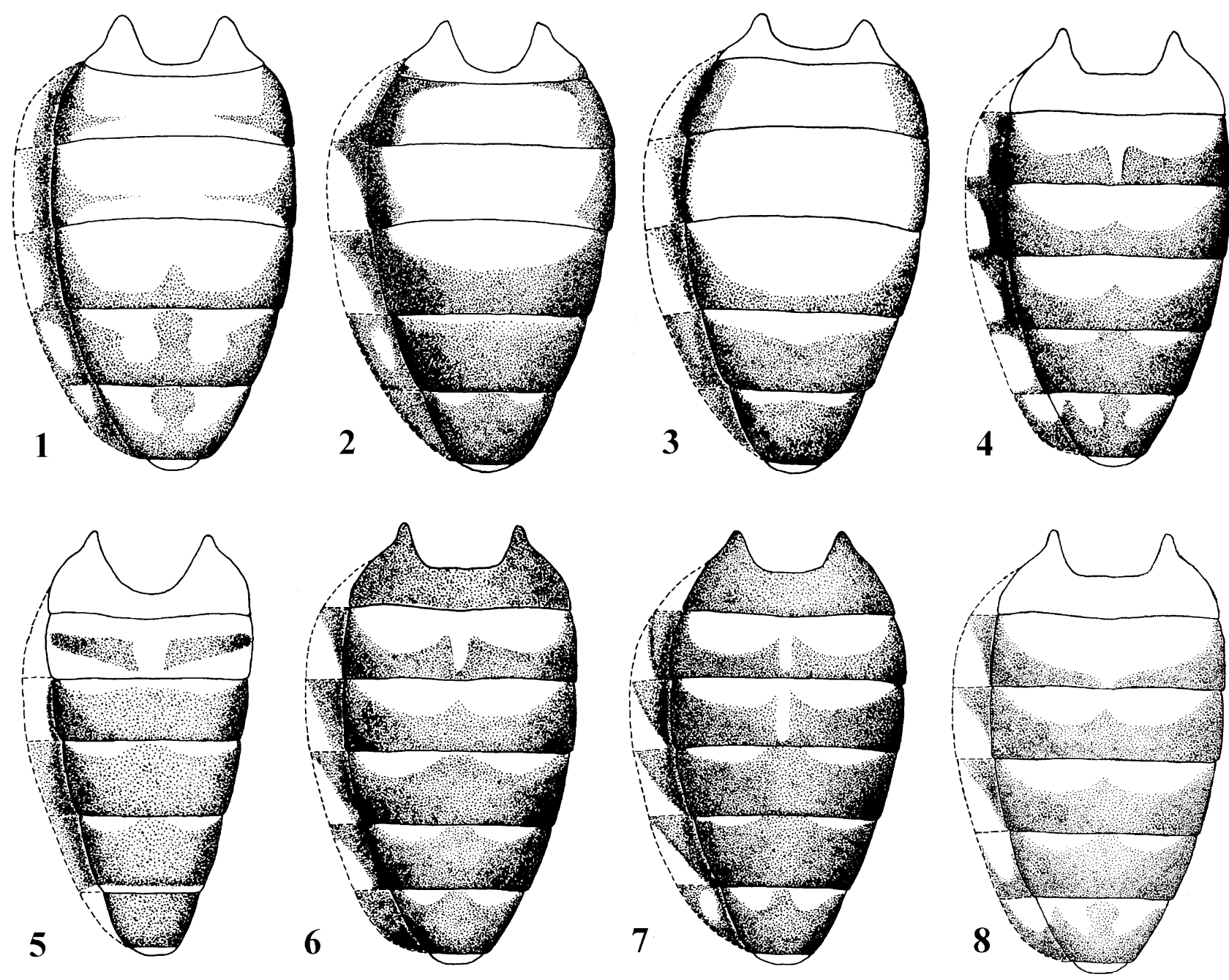

Figures 1-8. Abdominal tergite patterns in males. 1, Paraleucophenga argentosa (Okada, 1956); 2, Paraleucophenga emeiensis Sidorenko, 1998; 3, Paraleucophenga invicta (Walker, 1857); 4, Paraleucophenga javana Okada, 1988; 5, Paraleucophenga shimai Okada, 1988; 6, Paraleucophenga brevipenis sp. nov.; 7, Paraleucophenga longiseta sp. nov.; 8, Paraleucophenga anydactylia sp. nov.

(NSMT). Malaysia: one male, Sarawak, 25-27. vi.1975, H. Shima (NSMT).

Distribution: Taiwan; Nepal (Kathmandu); Malaysia (Sarawak); Indonesia (Java and Sumatra).

\section{PARALEUCOPHENGA JAVANA OKADA, 1988 \\ (FIGS 4, 11)}

Paraleucophenga javana Okada, 1988: 621.

Specimens examined: Holotype male and one male paratype: Indonesia, Tugu, Java, 17-30.vii.1971, T. Okada (NSMT). China: one male, Dinghushan, Zhaoqing, Guangdong, 6.v.2005, M.F. Xu; three males, Nonggang, Longzhou, Guangxi, 4.vi.1993, 23.viii.2004, ex. around human eyes, Y.S. Cui and
H.W. Chen; two males, Menglun, Xishuangbanna, Yunnan, 12.viii.2002, M.J. Toda.

Distribution: China (Guangdong, Guangxi, and Yunnan), Indonesia (Java).

\section{PARALEUCOPHENGA SHIMAI OKADA, 1988 (FIG. 5)}

Paraleucophenga shimai Okada, 1988: 621.

Specimens examined: Holotype male and three male paratypes: Thailand, Erawin Waterfall, 10.x.1975, H. Shima (NSMT). China: two males, Nonggang, Longsheng, Guangxi, 7.vii.1993, around human eyes, Y.S. Cui.

Distribution: China (Guangxi), Thailand. 

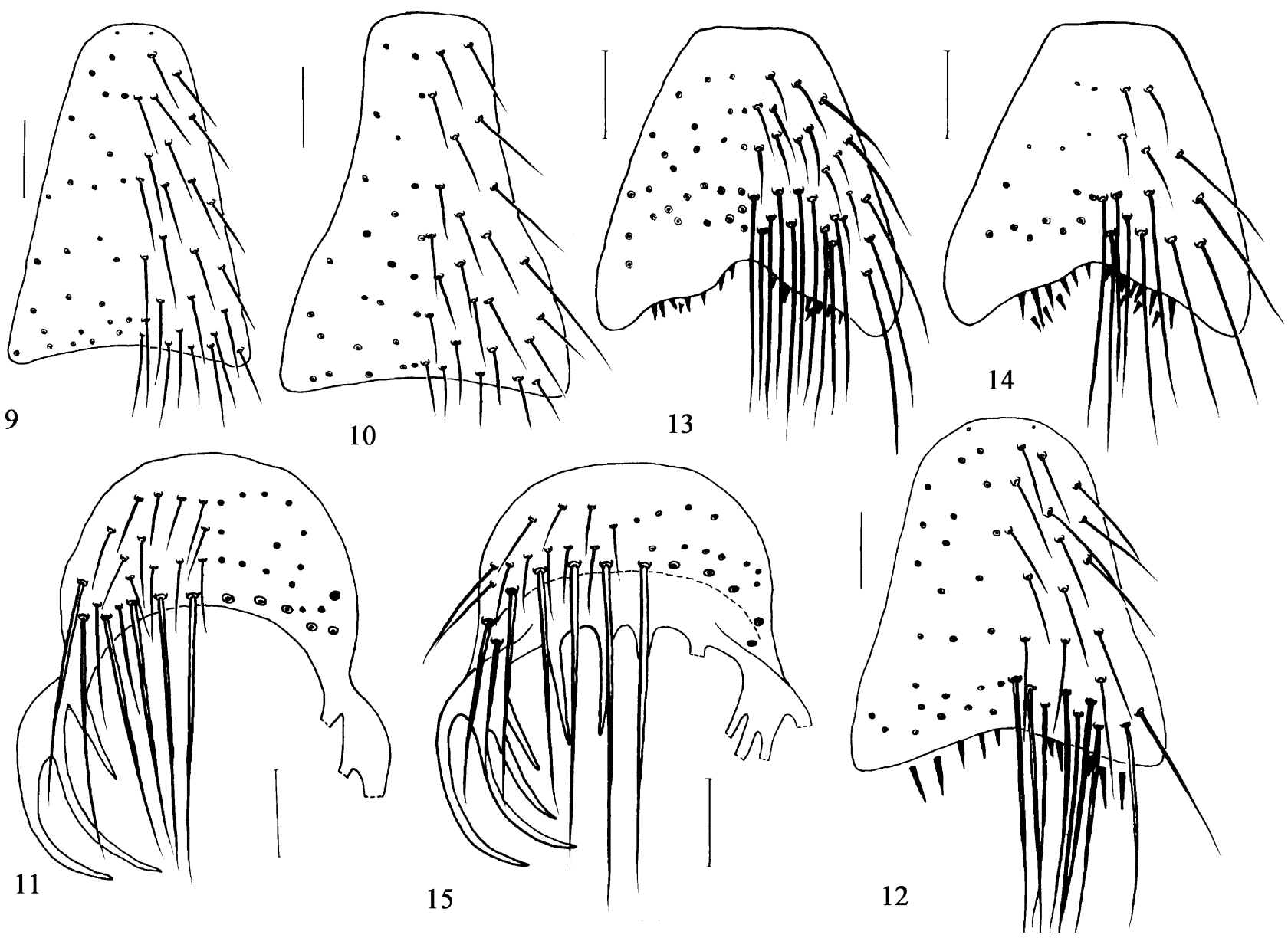

Figures 9-15. Abdominal fifth sternite in males. 9, Paraleucophenga argentosa (Okada, 1956); 10, Paraleucophenga emeiensis Sidorenko, 1998; 11, Paraleucophenga javana Okada, 1988; 12, Paraleucophenga brevipenis sp. nov.; 13, Paraleucophenga hirtipenis sp. nov.; 14, Paraleucophenga longiseta sp. nov.; 15, Paraleucophenga tanydactylia sp. nov. Scale bars: $0.1 \mathrm{~mm}$.

\section{PARALEUCOPHENGA BREVIPENIS SP. NOV.}

(FIGS 6, 12, 16, 17)

Specimens examined: Holotype male, China: Nanling, Ruyuan, Guangdong, 2.v.2004, around human eyes, H.W. Chen (SCAU). Paratype: two males, same data as the holotype except for 1.x.2004, M.F. Xu (SCAU) and 2.vii.2007, H.W. Chen (SCAU).

Etymology: A combination of the Latin words breviculus and penis, referring to the shorter aedeagus.

Description: Male. Abdominal first tergites brown; second to sixth tergites with brown bands. Fifth sternite with $c$. 22-24 long setae and a few spinules along posterior margin (Fig. 12).

Male terminalia. Surstylus with eight prensisetae near inner surface (Fig. 16). Paramere basally and apically each with four or five sensilla, submedially with 16-18 teeth (Fig. 17). Gonopods subapically with one sclerotized right process (Fig. 17). Aedeagal apodeme distally with one sclerotized right process (Fig. 17).

Measurements: BL, $4.56 \mathrm{~mm}$ in the holotype $(4.55 \mathrm{~mm}$ in 1 male paratype); ThL, $2.30 \mathrm{~mm}(2.15 \mathrm{~mm})$; WL, $4.60 \mathrm{~mm}(4.15 \mathrm{~mm})$; WW, $2.00 \mathrm{~mm}(1.90 \mathrm{~mm})$.

Indices: arb, 10/9-10; avd, 0.20 (0.20); adf, 1.25 (1.83); flw, 2.63 (3.17); FW/HW, 0.27 (0.27); ch/o, 0.05 (0.04); prorb, 0.42 (0.41); rcorb, 0.54 (0.74); vb, 0.24 (0.21); dcl, 0.49 (0.52); presctl, 0.39 (0.43); sctl, 1.22 (1.36); sterno, 0.38 (0.43); orbito, 1.20 (1.09); dcp, 0.29 (0.28); sctlp, 1.33 (1.25); C, 5.00 (5.45); 4c, 0.57 (0.50); 4v, 1.52 (1.45); 5x, 0.80 (0.93); ac, 1.20 (1.13); M, 0.38 (0.41); C3F, $0.53(0.55)$. 


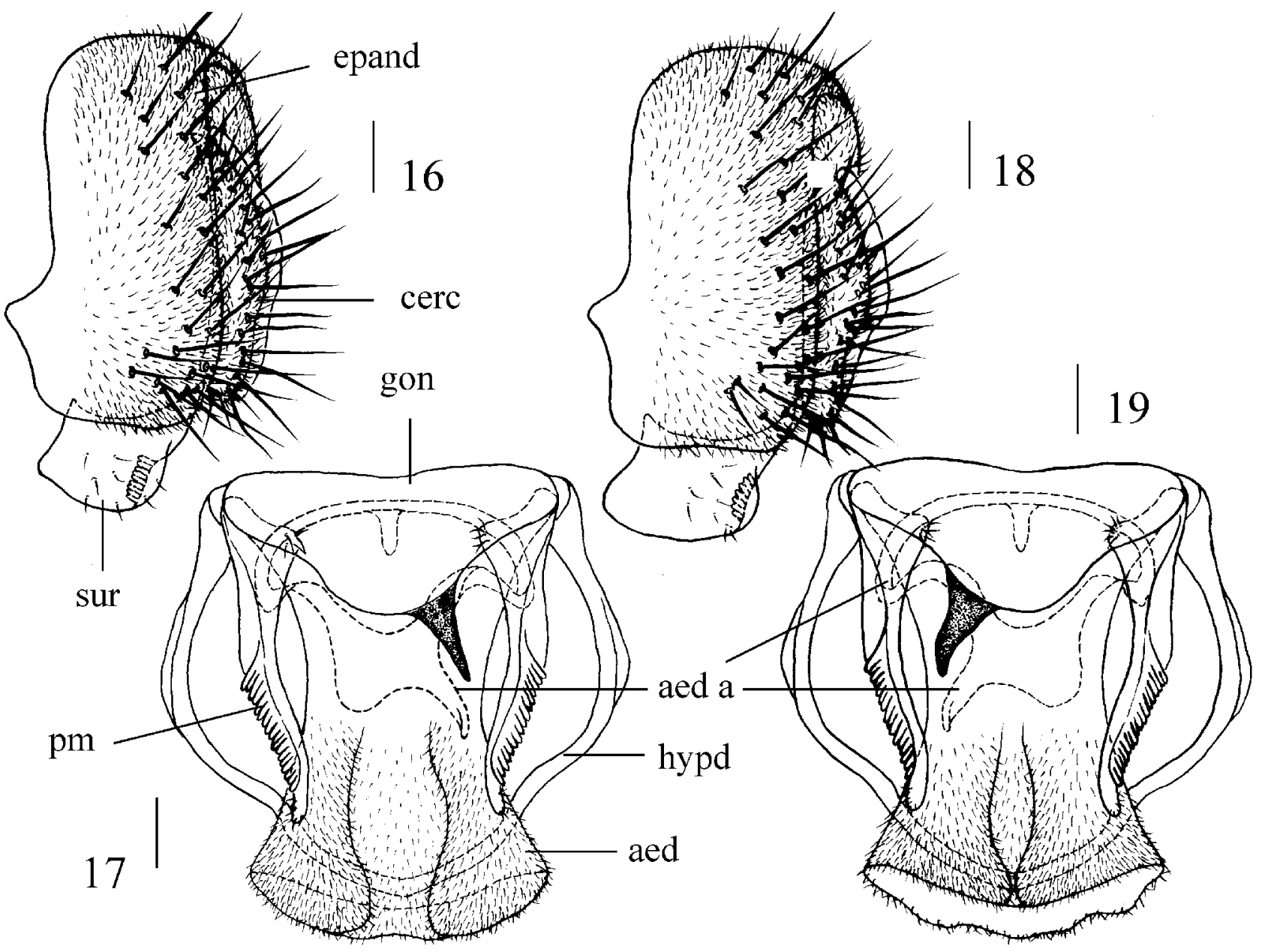

Figures 16-19. 16, 17, Paraleucophenga brevipenis sp. nov. $\sigma^{7} ; 18,19$, Paraleucophenga hirtipenis sp. nov. $\sigma^{\prime}$. 16, 18, epandrium (epand), cercus (cerc) and surstylus (sur); 17, 19, hypandrium (hypd), paramere (pm), gonopod (gon), aedeagus (aed), and aedeagal apodeme (aed a). Scale bars: $0.1 \mathrm{~mm}$.

\section{PARALEUCOPHENGA HIRTIPENIS SP. NOV.} (FIGS 13, 18, 19)

Specimens examined: Holotype male: China: Shibalianshan, Fuyuan, Qujing, Yunnan, 1.v.2006, ex. around human eyes, M.F. Xu (SCAU). Paratype: one male, same data as holotype (SCAU).

Etymology: A combination of the Latin words hirtus and penis, referring to the aedeagus with dense pubescence.

Description: Male. Abdominal first tergites brown; second to sixth tergites with brown bands (Fig. 6). Fifth sternite with 16-18 long setae and a few spinules along posterior margin (Fig. 13).

Male terminalia. Surstylus with seven prensisetae near inner surface (Fig. 18). Paramere basally and apically each with four or five sensilla, and submedially with 17-18 teeth (Fig. 19). Gonopods subapically with one sclerotized left process (Fig. 19). Aedeagal apodeme distally with one sclerotized left process (Fig. 19).

Measurements: BL, $4.60 \mathrm{~mm}$ in the holotype $(4.55 \mathrm{~mm}$ in one male paratype); ThL, $2.30 \mathrm{~mm}(2.25 \mathrm{~mm})$; WL, $4.45 \mathrm{~mm}(4.65 \mathrm{~mm})$; WW, $2.00 \mathrm{~mm}(2.00 \mathrm{~mm})$.

Indices: arb, 10/9-10; avd, 0.20 (0.20); adf, 1.88 (1.63); flw, 2.50 (2.63); FW/HW, 0.24 (0.29); ch/o, 0.06 (0.04); prorb, 0.50 (0.44); rcorb, 0.69 (0.70); vb, 0.32 (0.29); dcl, 0.51 (0.53); presctl, 0.38 (0.47); sctl, 1.13 (1.18); sterno, 0.76 (0.54); orbito, 1.04 (1.10); dcp, 0.36 (0.36); sctlp, 1.36 (1.36); C, 4.83 (4.69); 4c, $0.55(0.54) ; 4 \mathrm{v}$, 1.41 (1.50); 5x, 1.00 (0.90); ac, 1.20 (1.30); M, 0.41 (0.38); C3F, $0.52(0.47)$. 


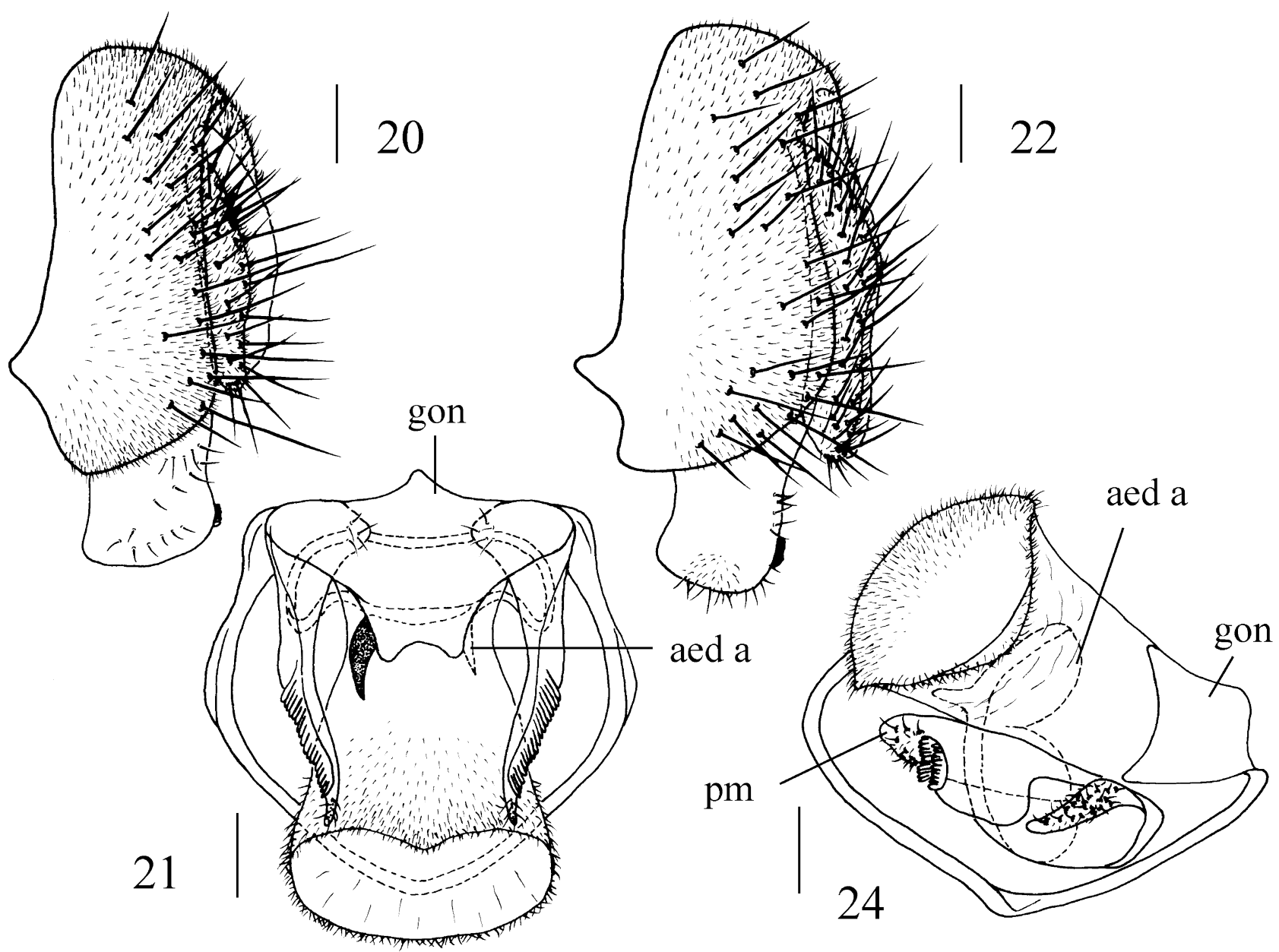

Figures 20-23. 20, 21, Paraleucophenga longiseta sp. nov. $\sigma^{7} ; 22,23$, Paraleucophenga tanydactylia sp. nov. $\sigma^{\top} .20,22$, epandrium, cercus, and surstylus; 21, 23, hypandrium, paramere, gonopod, aedeagus, and aedeagal apodeme. Scale bars: $0.1 \mathrm{~mm}$.

\section{PARALEUCOPHENGA LONGISETA SP. NOV.} (FIGS 7, 14, 20, 21)

Specimens examined: Holotype male: China, Leigongshan, Kaili, Guizhou, 800 m, 16.vii.2000, ex. around human eyes, H.W. Chen (SCAU). Paratypes: one male, same data as holotype (SCAU); one male, Guanshan, Yifeng, Jiangxi, ex. around human eyes, H.W. Chen (SCAU); two males, two females, Maoershan, Guangxi, 19.x.2004, on tree trunks, H.W. Chen (one male and one female in SEHU, one male and one female in SCAU); four males, Emeishan, Leshan, Sichuan $\left(29^{\circ} 44^{\prime} \mathrm{N}, 103^{\circ} 30^{\prime} \mathrm{E}\right)$, 1.vii.2007, ex. around human eyes, H.W. Chen (two males in KIZ, two males in SCAU).

Etymology: A combination of the Latin words longus and seta, referring to the fifth sternite with long setae.
Description: Male. Thorax, pleura, and scutellum brown. Scutellum with three small setae: one of them before the basal setae, and the others between the basal and the apical setae. Abdominal first tergites brown; second to sixth tergites with brown bands (Fig. 7). Fifth sternite with c. 18-20 long setae and a few spinules along posterior margin (Fig. 14).

Male terminalia. Surstylus with six prensisetae near inner surface (Fig. 20). Paramere each with five or six sensilla basally and apically (Fig. 21). Gonopod subapically with one sclerotized left process (Fig. 21). Aedeagal apodeme distally with one sclerotized right process (Fig. 21).

Measurements: BL, $4.96 \mathrm{~mm}$ in the holotype $(4.30 \mathrm{~mm}$ in one male paratype); ThL, $2.14 \mathrm{~mm}(2.20 \mathrm{~mm}) ; \mathrm{WL}$, $4.30 \mathrm{~mm}(4.00 \mathrm{~mm})$; WW, $1.58 \mathrm{~mm}(1.90 \mathrm{~mm})$. 
Indices: arb, 10/10-11; avd, 0.20 (0.19); adf, 2.20 (1.83); flw, 2.30 (3.50); FW/HW, 0.30 (0.28); ch/o, 0.05 (0.06); prorb, 0.60 (0.58); rcorb, $0.70(0.62)$; vb, 0.20 (0.24); dcl, 0.60 (0.57); presctl, 0.65 (0.34); sctl, 1.20 (1.18); sterno, 0.75 (0.72); orbito, 1.00 (1.10); dcp, 0.25 (0.37); sctlp, 1.50 (1.14); C, 5.50 (5.36); 4c, 0.44 (0.50); $4 \mathrm{v}, 1.31$ (1.36); 5x, 0.87 (1.13); ac, 1.23 (1.38); M, 0.81 (0.41); C3F, 0.38 (0.52).

\section{PARALEUCOPHENGA TANYDACTYLIA SP. NOV.}

(Figs 8, 15, 22, 23)

Specimens examined: Holotype male: China, Mengyang, Xishuangbanna, Yunnan, 13.ix.2002, on tree trunks, H.W. Chen (SCAU). Paratype: one male, same data as holotype (SCAU).

Etymology: A combination of the Greek words tanystys and dactylos, referring to the fifth sternite with finger-like processes.

Description: Male. Thoracic dark brown; pleura pale yellow, with large brown patches; scutellum brown, pale yellow along margin, with three small setae around basal setae. Abdominal first tergites entirely silvery white; second and sixth tergites with brown bands (Fig. 8). Fifth sternite with c. 12 long strong setae and 12 finger-like processes (Fig. 15).

Male terminalia. Surstylus with about eight prensisetae near inner surface (Fig. 22). Paramere basally strongly bulged, with dense sensilla, apically with dense sensilla and two rows of c. 23-25 teeth (Fig. 23). Gonopod distally broadened, forming one pair of curved, lobe-shaped, sclerotized processes (Fig. 23).

Measurements: $\mathrm{BL}, 4.80 \mathrm{~mm}$ in the holotype (4.82 $\mathrm{mm}$ in one male paratype); ThL, $1.78 \mathrm{~mm}(1.80 \mathrm{~mm})$; WL, $4.20 \mathrm{~mm}(4.12 \mathrm{~mm})$; WW, $1.70 \mathrm{~mm}(1.67 \mathrm{~mm})$.

Indices: arb, 10/9-10; avd, 0.20 (0.20); adf, 2.50 (2.40); flw, 2.20 (2.20); FW/HW, 0.30 (0.30); ch/o, 0.04 (0.04); prorb, 0.55 (0.55); rcorb, $0.55(0.60)$; vb, $0.20(0.20)$; dcl, 0.55 (0.55); presctl, 0.55 (0.55); sctl, 1.20 (1.20); sterno, 0.80 (0.80); orbito, 1.10 (1.10); dcp, 0.25 (0.25); sctlp, 1.50 (1.50); C, $5.71(5.40) ; 4 \mathrm{c}, 0.42(0.44) ; 4 \mathrm{v}$, 1.21 (1.18); 5x, 0.75 (0.81); ac, 1.08 (1.15); M, 0.39 (0.38); C3F, 0.57 (0.53).

\section{RESULTS OF THE PHYLOGENETIC ANALYSIS \\ DATA ANALYSIS}

The alignment of all of the ND2 sequences is 1035 nucleotide positions in length. The average nucleotide frequencies across species $(\mathrm{A}=35.6 \%, \mathrm{C}=11.6 \%$, $\mathrm{G}=7.7 \%$, and $\mathrm{T}=45.2 \%$ ) deviate greatly from the equilibrium of $25 \%$ for each nucleotide type, showing an A+ T-rich pattern.

The among-lineage base composition homogeneity is not rejected by the $\chi^{2}$ test. The nucleotide frequencies were similar among species $\left(\chi^{2}=13.9\right.$, d.f. $=45$, $P=1.00$ ). The test of substitution saturation indicates that observed Iss was significantly lower than Iss. $c$ (Iss $=0.2223$, and Iss. $c=0.7683$ for a symmetrical tree and 0.5747 for an extreme asymmetrical tree), indicating that the level of homoplasy in the ND2 sequences data is low.

The uncorrected pairwise genetic distances for ND2 sequences ranged from 0 to 0.194 (P. tanydactylia sp. nov. vs. $P$. emeiensis-SC or P. emeiensis-YN). The two sequences of $\boldsymbol{P}$. longiseta sp. nov. are identical, and so are those of $P$. argentosa. More or less intraspecific sequence variations are found within each of the species $\boldsymbol{P}$. brevipenis sp. nov., $P$. javana, and $P$. emeiensis, with the uncorrected genetic distance ( $p$-distance, i.e. the number of base differences per site) among conspecific forms ranging from 0.006 to 0.018 .

\section{PHYLOGENETIC RELATIONSHIPS}

Figure 24 show the trees deduced from the ND2 sequences (1035 sites, with 322 parsimonyinformative characters). The strict consensus of the two MP trees (Fig. 24A; tree length, TL = 677; consistency index, $\mathrm{CI}=0.7415$; retention index, $\mathrm{RI}=0.8573$ ) shows a largely similar topology to the ML tree (Fig. 24B; $-\ln L=4410.3499$ ). The confidence (posterior probability, $\mathrm{PP}$ ) of each node in the Bayesian tree (not shown), which has identical to the ML tree, is given on the corresponding node in the ML tree. In all of these trees, the monophyly of the genus Paraleucophenga is well supported with respect to the outgroup species (MP and ML BPs $=100$; Bayesian $\mathrm{PP}=1.00$ ), and each of the species represented by multiple populations proved to be monophyletic with strong confidence (MP BPs $=100 ; \quad \mathrm{ML} \quad \mathrm{BPs} \geq 88$; PPs $=1.00$ ). All of the trees indicate that $P$. emeiensis diverged first among the species of the genus Paraleucophenga, with the rest forming a monophyletic clade (MP and $\mathrm{ML} \mathrm{BPs}=100$; Bayesian $\mathrm{PP}=1.00$ ) that subsequently diverged into two subclades, one consisting of $P$. javana and $P$. tanydactylia sp. nov. (MP and ML BPs $=100 ; P P=1.00$ ), and the other consisting of $P$. argentosa, $P$. hirtipenis sp. nov., $P$. brevipenis sp. nov., and $P$. longiseta sp. nov. (MP and ML BPs $=96$ and 100 , respectively; $\mathrm{PP}=1.00$ ). Two species pairs are strongly supported in the latter subclade: the $\boldsymbol{P}$. hirtipenis sp. nov.-P. brevipenis sp. nov. pair (MP and ML BPs $=100$ and 96, respec- 
(a)

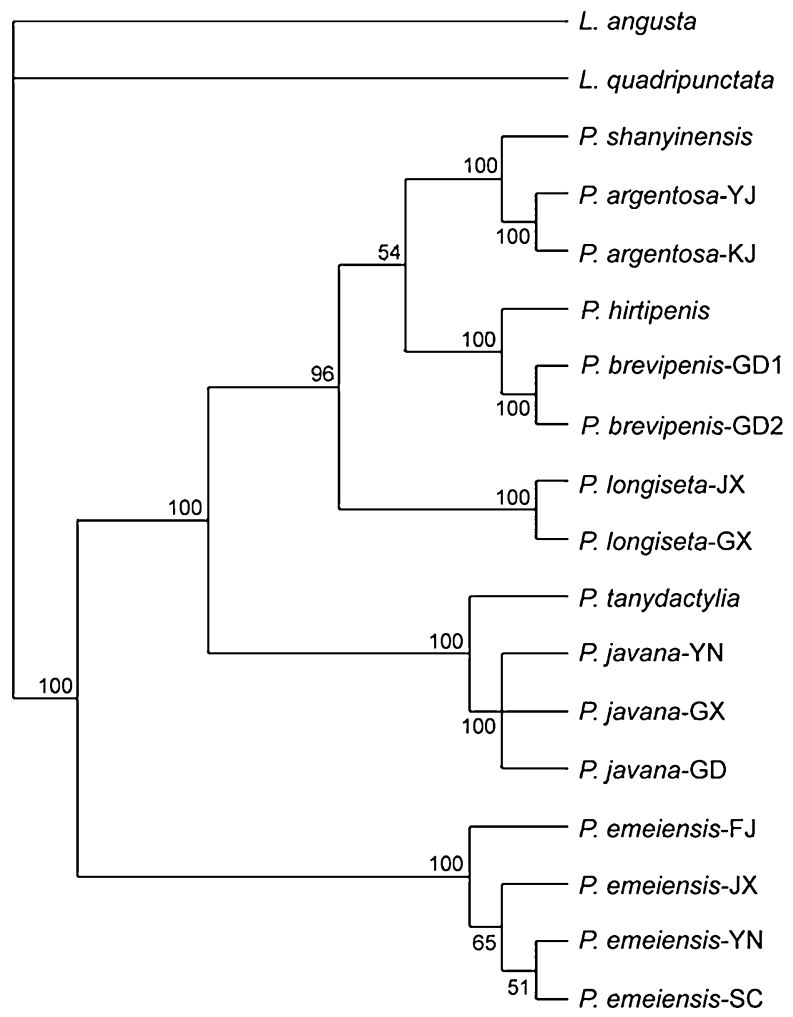

(b)

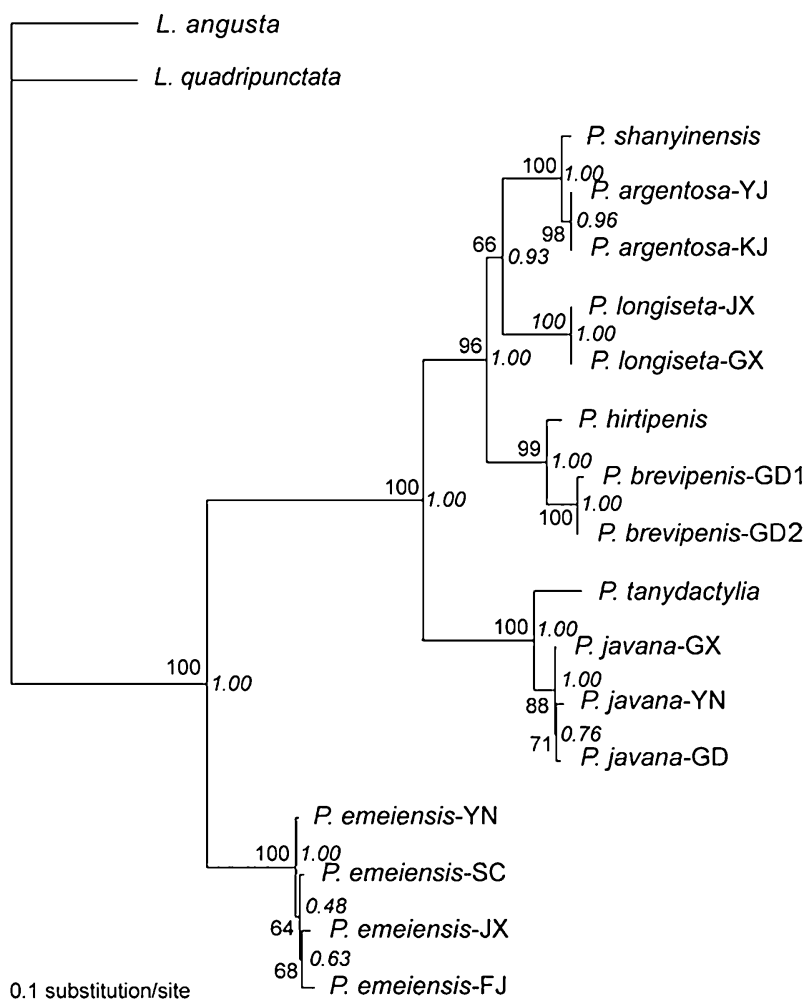

Figure 24. Phylogenetic trees deduced from the ND2 sequences. A, strict consensus tree of two equally parsimonious trees (677 steps). B, maximum likelihood (ML) tree. Numbers to the left of nodes in (A) and (B) indicate bootstrap proportions (\%) of maximum parsimony (MP) and ML methods, respectively; those to the right of nodes in (B) indicate the Bayesian posterior probabilities (PP).

tively; $\mathrm{PP}=1.00)$ and the $P$. shanyinensis-P. argentosa pair (MP and $\mathrm{ML} \quad \mathrm{BPs}=100 ; \mathrm{PP}=1.00)$. However, the MP tree differs from the ML and the Bayesian trees, in that it clusters the above two species pairs with low confidence $(\mathrm{BP}=54)$. In the latter two trees, the $P$. shanyinensis- $P$. argentosa pair is clustered with $\boldsymbol{P}$. longiseta sp. nov. $(\mathrm{BP}=66$; $\mathrm{PP}=0.93)$. Moreover, the MP tree yielded an intraspecific relationship for $P$. emeiensis as (FJ (JX (YN, SC))), which differs from those found in the ML and Bayesian trees, i.e. (YN (SC (JX, FJ))).

\section{ABBREVIATIONS}

BL, body length; ThL, thorax length; WL, wing length; WW, wing width; arb, dorsal branches/ventral branches of arista; avd, longest ventral branch/ longest dorsal branch of arista in length; adf, longest dorsal branch of arista/width of first flagellomere; flw, length/width of first flagellomere; FW/HW, frontal width/head width; ch/o, maximum width of gena/ maximum diameter of eye; prorb, proclinate orbital/ posterior reclinate orbital in length; rcorb, anterior reclinate orbital/posterior reclinate orbital in length; vb, subvibrissal/vibrissa in length; dcl, anterior dorsocentral/posterior dorsocentral in length; presctl, prescutellar/posterior dorsocentral in length; sctl, basal scutellar/apical scutellar in length; sterno, anterior katepisternal/posterior katepisternal in length; orbito, distance between proclinate and posterior reclinate orbitals/distance between inner vertical and posterior reclinate orbital; dcp, length distance between ipsilateral dorsocentrals/cross distance between anterior dorsocentrals; sctlp, distance between ipsilateral scutellars/cross distance between apical scutellars; C, second costal section between subcostal break and $R_{2+3}$ /third costal section between $R_{2+3}$ and $R_{4+5}$; $4 c$, third costal section between $R_{2+3}$ and $R_{4+5} / M_{1}$ between $\mathrm{r}-\mathrm{m}$ and $\mathrm{dm}-\mathrm{cu} ; 4 \mathrm{v}, \mathrm{M}_{1}$ between $\mathrm{dm}-\mathrm{cu}$ and wing margin/ $/ \mathrm{M}_{1}$ between $\mathrm{r}-\mathrm{m}$ and $\mathrm{dm}-\mathrm{cu}$; $5 \mathrm{x}, \mathrm{CuA}_{1}$ between $\mathrm{dm}-\mathrm{cu}$ and wing margin/dm-cu between $\mathrm{M}_{1}$ and $\mathrm{CuA}_{1}$; ac, third costal section between $\mathrm{R}_{2+3}$ and $R_{4+5} /$ distance between distal ends of $R_{4+5}$ and $M_{1} ; M$, $\mathrm{CuA}_{1}$ between $\mathrm{dm}$-cu and wing margin/ $\mathrm{M}_{1}$ between $\mathrm{r}-\mathrm{m}$ and $\mathrm{dm}-\mathrm{cu}$; C3F, length of heavy setation in third costal section/(length of heavy setation in third costal 
section + length of light setation in third costal section).

\section{DISCUSSION}

\section{SYNONYM}

All of the phylogenetic trees (Fig. 24) suggest a sister relationship between the two previously recognized species $P$. shanyinensis and $P$. argentosa, with high confidence. The divergence in ND2 sequences between $P$. shanyinensis and $P$. argentosa $(\mathrm{P}$ distance $=0.019)$ is comparable with those among the three populations of $P$. emeiensis (average p-distance $=0.015$ ), whereas this divergence is relatively smaller than the evaluated ND2 sequence divergence between populations of Drosophila (Drosophila) tsigana Burla and Gloor, 1952 from China and Japan (Mean $\mathrm{p}$-distance $=0.036$; sequences from Wang et al., 2006). Some larger divergences in ND2 sequences can be evaluated among the closely related species Drosophila (Sophophora) subobscura Collin, 1936, Drosophila (Sophophora) ambigua Pomini, 1940, and Drosophila (Sophophora) guanche Monclús, 1976 (mean p-distance $=0.045$; sequences from Gao et al., 2007). As no morphological diagnostic character has been found to distinguish $P$. shanyinensis from $P$. argentosa, we tentatively regard $P$. shanyinensis Chen $\&$ Toda (1994) as a junior synonym of $P$. argentosa Okada (1956), and will hereafter suppress the name shanyinensis in this present paper.

\section{ENANTIOMORPHISM IN GENITALIA STRUCTURE}

The inner genitalia of the two species $\boldsymbol{P}$. brevipenis sp. nov. and $\boldsymbol{P}$. hirtipenis sp. nov. seem to be enantiomorphous. Such a phenomenon was previously reported in other drosophilid species: for example, in Phortica speculum (Máca \& Lin, 1993) the phallic organs have a reversed structural arrangement in both the holotype and the paratype (Máca \& Lin, 1993). Moreover, mirror-image variation was found in the asymmetric structure of the vertical process of gonopods for Phortica brachychaeta Chen \& Toda, 2005 (Chen, Toda \& Gao, 2005). Our studies elsewhere have revealed that the ND2 nucleotide sequences are identical between the different enantiomorphism types in either Phortica speculum or Phortica brachychaeta (X.L. Wang, H.L. Cao, S. Prigent, J.J. Gao, H. Watabe, Y.P. Zhang, \& H.W. Chen, unpubl. data).

\section{PhYLOGENETIC RELATIONSHIPS AMONG SPECIES OR SPECIES CLUSTERS}

The MP tree yielded a branching order among $\boldsymbol{P}$. longiseta sp. nov., the $P$. shanyinensis $-P$. argentosa pair, and the $\boldsymbol{P}$. hirtipenis sp. nov.-P. brevipenis sp. nov. pair that differs from those in the ML (and in the Bayesian) tree(s). However, neither of the branching orders seems to be reliable, as the corresponding node confidences are relatively low. It could be noted in the two MP trees (not shown) that the branch leading to the $P$. shanyinensis- $P$. argentosa and $P$. hirtipenis sp. nov.-P. brevipenis sp. nov. pairs is quite a bit shorter than those leading to the other species (or species clusters), and so is the branch leading to $P$. shanyinensis $-P$. argentosa and $P$. longiseta in the ML tree (Fig. 24B). This means that these lineages diverged from one another in very short succession. No essential homoplasy was found in our sequence data, so it is likely that the phylogenetic difficulty associated with the above lineages is the result of a different assortment of the ancestral polymorphism (O'hUigin et al., 2002).

We used the program Spectrum 2.3 (Charleston, 1998), which is capable of showing both the support and the conflict for different groupings, to perform a spectral analysis. According to the 'Evaluate Bipartition' calculation, the spectral analysis lent good support to the nodes common to the MP and ML trees. The support for (P. argentosa, $\boldsymbol{P}$. hirtipenis sp. nov., $P$. brevipenis sp. nov., and $P$. longiseta sp. nov.) as a split (0.01277) was high, with low normalized conflict (0.00374). However, different support and conflict values were found when the two splits, $(P$. argentosa and $\boldsymbol{P}$. longiseta sp. nov.) in the ML tree and (P. argentosa, $P$. hirtipenis sp. nov., and $P$. brevipenis sp. nov.) in MP tree, were divided. The support for the former as a split (0.00196) was relatively higher than the support for the latter (0.00098); moreover, the former value of the normalized conflict (0.00170) was relatively lower than the latter (0.00442). Support for (P. hirtipenis sp. nov., $\boldsymbol{P}$. brevipenis sp. nov., and $P$. longiseta sp. nov.) as a split (0.00098) was lower than the normalized conflict (0.00272). Based on the above results, the relationship reflected in the ML tree, i.e. (P. argentosa and $\boldsymbol{P}$. longiseta sp. nov.) as a split, should be considered as more reliable.

\section{MORPHOLOGICAL VS. MOLECULAR AFFINITIES}

In this study, the sibling species relationship between $\boldsymbol{P}$. hirtipenis sp. nov. and $\boldsymbol{P}$. brevipenis sp. nov. or between $\boldsymbol{P}$. tanydactylia sp. nov. and $P$. javana were strongly supported. These close relationships are congruent with the special morphological similarity between each of the species pairs: P. tanydactylia sp. nov. resembles $P$. javana in the fifth sternite with long, finger-like processes, and paramere basally and apically with sensilla, subapically with tooth row(s); $\boldsymbol{P}$. hirtipenis sp. nov. resembles $\boldsymbol{P}$. brevipenis sp. 
nov. in the fifth sternite with long, strong setae and a few spinules along posterior margin, and in gonopods subapically with one sclerotized process, and aedeagal apodeme distally with one sclerotized process.

Some prominent morphological characters appear to suggest incongruent interspecific relationships compared with the molecular data: with respect to the morphological trait of the fifth sternite, $P$. argentosa appears to be closer to $P$. emeiensis than to $\boldsymbol{P}$. longiseta sp. nov., and $P$. longiseta sp. nov. appears to be closer to $\boldsymbol{P}$. hirtipenis sp. nov./P. brevipenis sp. nov. than to $P$. argentosa; whereas with respect to the colour patterns of male abdominal tergites, $\boldsymbol{P}$. longiseta sp. nov. and $\boldsymbol{P}$. brevipenis sp. nov. are closer to each other than either is to the other species.

\section{ACKNOWLEDGEMENTS}

We are grateful to Profs T. Saigusa (Kyushu University), T. Aotsuka (Tokyo Metropolitan University), and Y.P. Zhang (KIZ) for help in the field survey. We thank Profs H. Watabe (Hokkaido University of Education) and M.J. Toda (Hokkaido University), and Mrs M.F. $\mathrm{Xu}$, H.Z. Cao and J.J. Jiang (SCAU) for presenting us with specimens, and Dr A. Shinohara (NSMT) for checking specimens at NSMT. This work was supported by the Japan Society for the Promotion of Science (Grant Nos 12375002 and 01111), the Scientific Research Foundation for the Returned Overseas Chinese Scholars, and Science Foundation of Doctor Subjects, State Education Ministry of China (Grant No. 20050564016), and the National Natural Science Foundation of China (Grant No. 30470212).

\section{REFERENCES}

Bächli G. 1971. Leucophenga und Paraleucophenga (Diptera Brachycera), fam. Drosophilidae. In: M.G.F. de Witte, W. Adam, A. Janssens, L. van Meel, R. Verheven, eds. Exploration du Parc National de l'Upemba. Institut des Parcs nationaux de congo et du Rwanda, Bruxelles.

Charleston MA. 1998. Spectrum: spectral analysis of phylogenetic data. Bioinformatics 14: 98-99.

Chen HW, Toda MJ. 2001. A revision of the Asian and European species in the subgenus Amiota Loew (Diptera, Drosophilidae) and establishment of species-groups based on phylogenetic analysis. Journal of Natural History 35: 1517-1563.

Chen HW, Toda MJ, Gao JJ. 2005. The Phortica (s. str.) foliiseta species-complex (Diptera, Drosophilae) from china and its adjacent countries. Acta Zootaxonomica Sinica 30: 419-429.

Chen HZ, Toda MJ. 1994. Six new species of the Drosophilidae (Diptera) from Eastern China. Japan Journal of Entomology 62: 537-554.
Duda O. 1924. Die Drosophiliden (Dipteren) des Deutschen Entomologischen Institutes der Kaiser Wilhelm-Gesellschaft. Archiv der Freunde der Naturgeschichte in Mecklenburg $\mathbf{9 0}$ (A): 235-259.

Duda O. 1939. Revision der Afrikanischen Drosophiliden (Diptera). I. Annales Musei Nationalis Hungaric 32: 1-57.

Gao JJ, Watabe H, Aotsuka T, Pang JF, Zhang YP. 2007. Molecular phylogeny of the Drosophila obscura species group, with emphasis on the Old World species. BMC Evolutionary Biology 7: 87.

Grimaldi DA. 1990. A phylogenetic, revised classification of genera in the Drosophilidae (Diptera). Bulletin of the American Museum of Natural History 197: 1-139.

Hendel F. 1914. Acalyptrate musciden (Diptera). Supplementa Entomologica 3: 90-117.

Kumar S, Tamura K, Nei M. 2004. MEGA3: integrated software for Molecular Evolutionary Genetics Analysis and sequence alignment. Briefings in Bioinformatics 5: 150-163.

Lin FJ, Wheeler MR. 1972. The Drosophilidae of Taiwan, I. Genera Leucophenga and Paraleucophenga. University of Texas Publication 7213: 237-256.

Máca J, Lin FJ. 1993. The Drosophilidae of Taiwan: genus Amiota, subgenus Phortica. Buletin of the Institute of Zoology, Academia Sinica 32: 171-183.

O'hUigin C, Satta Y, Takahata N, Klein J. 2002. Contribution of homoplasy and of ancestral polymorphism to the evolution of genes in anthropoid primates. Molecular Biology and Evolution 19: 1501-1503.

Okada T. 1956. Systematic study of Drosophilidae and allied families of Japan. Tokyo: Gihodo Co. Ltd, 1-183.

Okada T. 1988. A revision of the genus Pararhinoleucophenga Duda and Paraleucophenga Hendel (Diptera, Drosophilidae), with special regard to Archestinic Characters. Konty $\hat{u}$ 56: $618-624$.

Okada T. 1989. A proposal of establishing tribes for the family Drosophilidae with key to tribes and genera (Diptera). Zoological Science 6: 391-399.

Park J. 1999. Molecular phylogenetic studies of the Drosophila (Drosophila) virilis section (Diptera, Drosophilidae). $\mathrm{PhD}$ Thesis, Tokyo Metropolitan University.

Posada D, Crandall KA. 1998. Modeltest: test the model of DNA substitution. Bioinformatics 14: 817-818.

Ronquist F, Huelsenbeck JP. 2003. MrBayes 3: Bayesian phylogenetic inference under mixed models. Bioinformatics 19: $1572-1574$.

Sambrook J, Fritsch EF, Maniatis T. 1989. Molecular cloning: a laboratory manual, 2nd edn. New York: Cold Spring Harbor Laboratory Press, 1-126.

Sidorenko VS. 1998. New data on Asian Drosophilid flies (Diptera, Drosophilidae). Part 3. Far Eastern Entomologist 56: $1-8$.

Singh BK, Negi NS. 1992. Two new and one unrecorded species of Drosophilidae from Uttarakhand, India (Insecta, Diptera). Senckenbergiana Biologica 72: 321-327.

Swofford DL. 2003. PAUP*. Phylogenetic Analysis Using Parsimony (* and other methods). Version 4. Sunderland, MA: Sinauer Associates.

Thompson JD, Higgins DG, Gibson TJ. 1994. CLUSTAL 
W: improving the sensitivity of progressive multiple sequence alignment through sequence weighting, positionspecific gap penalties and weight matrix choice. Nucleic Acids Research 22: 4673-4680.

Walker F. 1857. Catalogue of the Dipterous insects collected at Sarawak, Borneo, by Mr. A.R. Wallace, with descriptions of new species. Journal of the Proceedings of the Linnean Society Zoology 4: 105-140.
Wang BC, Park J, Watabe H, Gao JJ, Xiangyu J, Aotsuka T, Chen HW, Zhang YP. 2006. Molecular phylogeny of the Drosophila virilis section (Diptera: Drosophilidae) based on mitochondrial and nuclear sequences. Molecular Phylogenetics and Evolution 40: 484-500.

Xia XH, Zh X, Salemi M, Chen L, Wang Y. 2003. An index of substitution saturation and its application. Molecular Phylogenetics and Evolution 26: 1-7. 